Provided for non-commercial research and education use. Not for reproduction, distribution or commercial use.

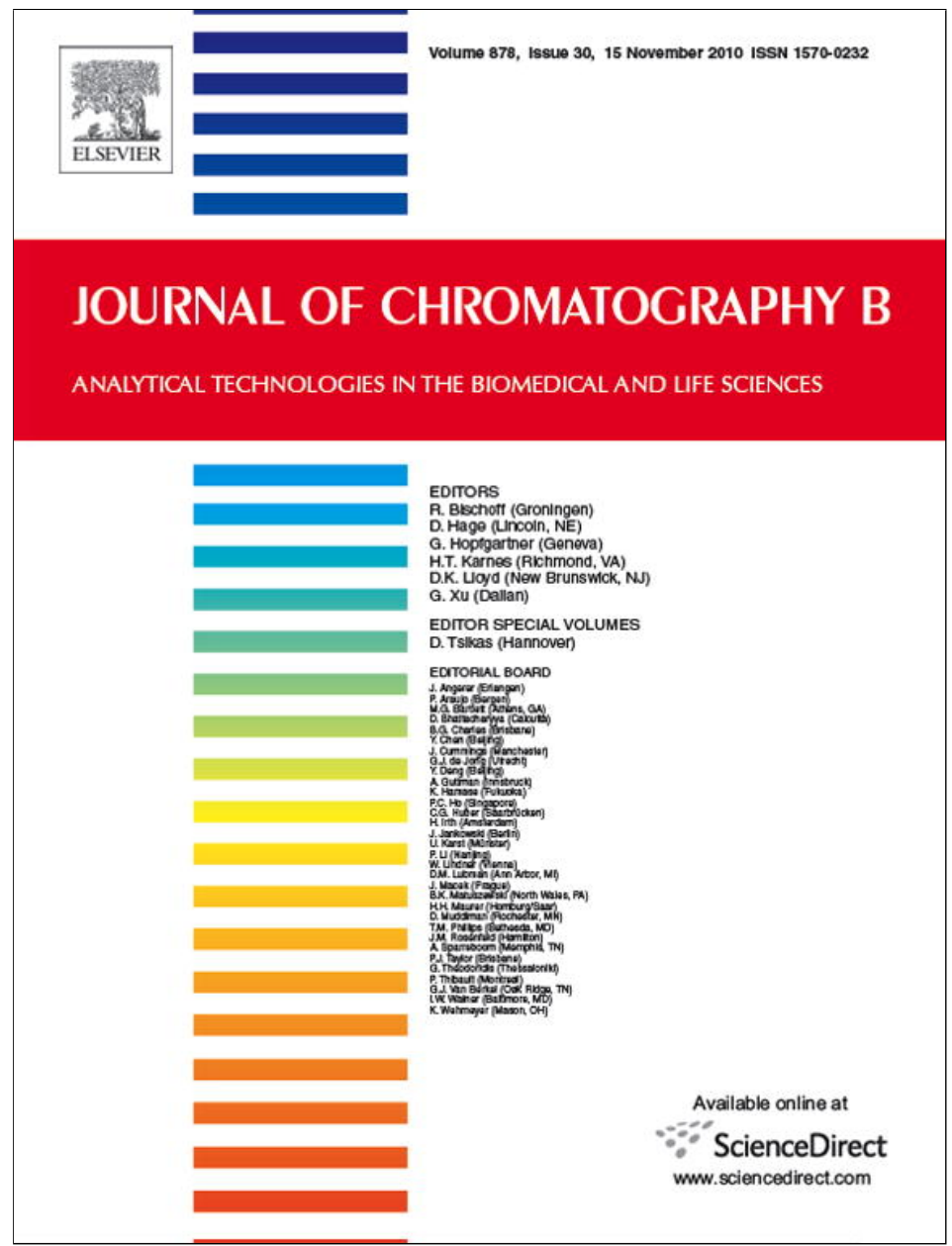

This article appeared in a journal published by Elsevier. The attached copy is furnished to the author for internal non-commercial research and education use, including for instruction at the authors institution and sharing with colleagues.

Other uses, including reproduction and distribution, or selling or licensing copies, or posting to personal, institutional or third party websites are prohibited.

In most cases authors are permitted to post their version of the article (e.g. in Word or Tex form) to their personal website or institutional repository. Authors requiring further information regarding Elsevier's archiving and manuscript policies are encouraged to visit:

http://www.elsevier.com/copyright 


\title{
Determination of 17 illicit drugs in oral fluid using isotope dilution ultra-high performance liquid chromatography/tandem mass spectrometry with three atmospheric pressure ionizations
}

\author{
I-Ting Wang, Yu-Ting Feng, Chia-Yang Chen* \\ Institute of Environmental Health, College of Public Health, National Taiwan University, 17 Hsu-Chou Rd., Taipei City 10055, Taiwan
}

\section{A R T I C L E I N F O}

\section{Article history:}

Received 28 May 2010

Accepted 20 September 2010

Available online 29 September 2010

\section{Keywords:}

UHPLC-MS/MS

Electrospray ionization

Atmospheric pressure chemical ionization

Atmospheric pressure photoionization

Matrix effect

\begin{abstract}
A B S T R A C T
The collection of oral fluid for drug testing is easy and non-invasive. This study developed a drug testing method using ultra-high performance liquid chromatography/tandem mass spectrometry (UHPLC-MS/MS) in selected-reaction monitoring (SRM) mode. We tested the method on the analysis of four opiates and their metabolites, five amphetamines, flunitrazepam and its two metabolites, and cocaine and its four metabolites in oral fluid. $100-\mu \mathrm{L}$ samples of oral fluid were diluted with twice the amount of water then spiked with isotope-labeled internal standards. After the samples had undergone high-speed centrifugation for $20 \mathrm{~min}$, we analyzed the supernatant. The recovery of the sample preparation ranged from 81 to $108 \%$. We compared the performance of electrospray ionization (ESI), atmospheric pressure chemical ionization (APCI) and atmospheric pressure photoionization (APPI). The ion suppression of most analytes on ESI (28-78\%) was lower than that of APCI and APPI. A post-column flow split (5:1) did not reduce the matrix effect on ESI. Direct APPI performed better than dopant-assisted APPI using toluene. ESI, APCI and APPI limits of quantitation mostly ranged from 0.11 to $1.9 \mathrm{ng} / \mathrm{mL}, 0.02$ to $2.2 \mathrm{ng} / \mathrm{mL}$ and 0.02 to $2.1 \mathrm{ng} / \mathrm{mL}$, respectively, but were much higher on amphetamine and ecgonine methyl ester (about $2.7-4.7 \mathrm{ng} / \mathrm{mL}, 8.7-14 \mathrm{ng} / \mathrm{mL}$, and $10-19 \mathrm{ng} / \mathrm{mL}$, respectively). Most of the bias percentages (accuracy) and relative standard deviations (precision) on spiked samples were below $15 \%$. This method greatly simplifies the process of sample preparation and shortens the chromatographic time to only 7.5 min per run and is able to detect analytes at sub-ppb levels.
\end{abstract}

(c) 2010 Elsevier B.V. All rights reserved.

\section{Introduction}

Drug abuse comes with serious health problems, increased criminal activity, and the spread of some diseases. According to the 2008 World Drug Report, almost 5\% of the world's populations have abused at least one drug in the past twelve months and $0.6 \%$ of the world's adults are severely drug addicted [1].

Morphine, heroin (diacetyl morphine) and codeine are narcotics. Amphetamine and its derivatives, including methamphetamine, 3,4-methylenedioxymethamphetamine (MDMA), 3,4-methylenedioxyethamphetamine (MDEA), and 3,4methylenedioxyamphetamine (MDA), act to stimulate the central nervous system (CNS), increasing alertness and decreasing fatigue and appetite. Flunitrazepam, a hypnotic for short-term treatment of chronic insomnia, can debilitate persons and is often used as a date rape drug or for robbery. Cocaine is a CNS stimulant and

\footnotetext{
* Corresponding author.

E-mail address: dbms@ntu.edu.tw (C.-Y. Chen).
}

topical anaesthetic able to produce a euphoric state similar to that induced by amphetamines.

Oral fluid has emerged for drug testing for the last twenty years [2,3]. It is a much simpler matrix than traditional specimens like urine and plasma because it is composed of $99 \%$ water, $0.3 \%$ proteins, and $0.3 \%$ mucin [4]. Its collection is non-invasive, easily performed, and can be done under surveillance or in clinics and workplaces [4], minimizing the chances of sample substitution or adulteration. Parent drugs in oral fluid are usually found in concentrations highly correlated with those in plasma [5-7] and they are much less susceptible to dilution by fluid intake [8-13].

Certain chemicals are better detected than others in suited in the oral fluid from users of illicit drugs. Because heroin has a short half-life in the blood (2-7 min), a better biomarker of heroin use might be 6 -acetylmorphine in the oral fluid $[14,15]$. Codeine is the primary chemical found in plasma and oral fluids of codeine users [16,17]. Amphetamine and methamphetamine are found at higher concentrations in the oral fluid than in the plasma if they are taken orally $[18,19]$. MDMA and its metabolite MDA are the major chemicals found in the oral fluid from MDMA users [20,21]. 
The flunitrazepam metabolite, 7-aminoflunitrazepam, is the primary analyte detected in the oral fluid in flunitrazepam users [22]. Besides cocaine, its major metabolite benzoylecgonine is also the main detectable chemical in the oral fluid in cocaine users $[10,15,23]$.

Illicit drugs can be detected in oral fluid using gas chromatography-mass spectrometry (GC-MS) or GC-tandem MS (GC-MS/MS) with the use of solid-phase extraction (SPE) $[3,24]$, solid-phase microextraction [25], small volume liquid extraction [26], or a single-step extraction and derivatization [27]. The limits of quantitation (LOQs) for these methods range between 5 and $25 \mathrm{ng} / \mathrm{mL}$. Another method, liquid chromatography (LC) coupled with MS/MS, does not require chemical derivatization. This method is often more sensitive than GC-MS, and has LOQs ranging from 0.5 to $2 \mathrm{ng} / \mathrm{mL}$ [28-31]. It is especially useful when the amount of oral fluid is limited as is often found in samples from amphetamine users who often have "dry mouth" [32,33].

Matrix effects can influence the efficiency of ionization and measurement of analytes and confound LC-MS(/MS) results [32,34-36]. To reduce their effects, oral fluid can be pretreated with SPE because it usually provides lower ion suppression on electrospray ionization (ESI) than either liquid-liquid extraction (LLE) or protein precipitation $[31,33,37,38]$. However, SPE concentrates some matrix components as well as the analytes and it may not lower ion suppression any better than a simple dilution of samples with water [37]. In addition to a better sample preparation, use of different ionization interface may also reduce matrix effects. For example, two studies performed by Dams et al. found that samples subjected to atmospheric pressure chemical ionization (APCI) were less susceptible to matrix effects than those undergoing ESI when measuring the amount of illicit drugs in biofluids $[37,39]$.

Atmospheric pressure photoionization (APPI) is a relatively new means of ionization. This method uses an ultraviolet lamp to emit photons and initiates the ionization by direct interaction with analytes or indirect ionization via dopant $[40,41]$. To date, no published paper has assessed the use of APPI to analyze illicit drugs in oral fluid. In addition, there has been a recent increase in the use of ultra-high performance liquid chromatography (UHPLC) in bio-analysis because it provides better resolution and higher throughput than high-performance liquid chromatography (HPLC) $[42,43]$. Because UHPLC columns can be packed with smaller particles (less than $2.0 \mu \mathrm{m}$ ), the resulting increase in flow rates can shorten the chromatographic time and sharpen the peaks, providing better sensitivity and peak capacities without sacrificing separation efficiencies.

The aim of this study was to develop and assess analytical methods involving the use of UHPLC-MS/MS combined with ESI, APCI and APPI to determine four opiates and metabolites (heroin, morphine, 6-actylmorphine, codeine), five amphetamines (amphetamine, methamphetamine, MDMA, MDA, MDEA), flunitrazepam and its two metabolites (7-aminoflunitrazepam and $\mathrm{N}$-desmethylflunitrazepam), cocaine and its four metabolites (norcocaine, benzoylecgonine, ecgonine methyl ester, and cocaethylene) in oral fluid. The sample was pretreated with steps of dilution and centrifugation before instrumental analysis; the matrix effect and detection sensitivity on the three different ionization sources were evaluated. Use of stable isotope-labeled internal standards for quantitation proved to be precise and accurate. This method greatly simplifies sample preparation and requires only 7.5-min chromatography including re-equilibration. The improved sensitivity greatly enhances the detection window for the detection of illicit drugs in oral fluid and the high throughput makes it possible to process a large number of samples in short amount of time.

\section{Experimental}

\subsection{Chemicals and reagents}

We obtained heroin, 6-acetylmorphine, cocaine, norcocaine: hydrochloride, ecgonine methyl ester, and cocaethylene in acetonitrile at $1.0 \mathrm{mg} / \mathrm{mL}, 7$-aminoflunitrazepam in acetonitrile at $100 \mu \mathrm{g} / \mathrm{mL}$, morphine, codeine, (+/-)-amphetamine, (+/-)methamphetamine, (+/-)-MDMA, (+/-)-MDA, (+/-)-MDEA, flunitrazepam, $N$-desmethylflunitrazepam, and benzoylecgonine in methanol at $1.0 \mathrm{mg} / \mathrm{mL}$ from Cerilliant (Austin, TX, USA). Their molecular structures are shown in Fig. 1. We also purchased the isotope-labeled standards, including heroin- $\mathrm{D}_{9}, 6$-acetylmorphine$D_{6}, 7$-aminoflunitrazepam- $D_{7}$, cocaine- $D_{3}$, ecgonine methyl ester$D_{3}$ and cocaethylene- $D_{8}$ in acetonitrile at $100 \mu \mathrm{g} / \mathrm{mL}$, morphine- $D_{6}$, codeine- $\mathrm{D}_{6}(+/-)$-amphetamine- $\mathrm{D}_{8},(+/-)$-methamphetamine- $\mathrm{D}_{8}$, (+/-)-MDMA-D $,(+/-)-M D A-D_{5},(+/-)-M D E A-D_{5}$, flunitrazepam$\mathrm{D}_{7}, N$-desmethylflunitrazepam- $\mathrm{D}_{4}$ and benzoylecgonine- $\mathrm{D}_{8}$ in methanol at $100 \mu \mathrm{g} / \mathrm{mL}$ from Cerilliant.

LC-MS grade acetonitrile and methanol (used as mobile phase), HPLC-grade methanol, acetonitrile, dichloromethane, $n$-heptane and acetone were purchased from J.T. Baker (Philipsburg, NJ, USA). GC-grade dimethyldichlorosilane (DMDCS) was purchased from Supelco (Belletonte, PA, USA), toluene from Mallinckrodt Baker (Phillipsburg, NJ, USA) and analytical grade ammonium acetate and ammonium formate were obtained from Sigma-Aldrich (St. Louis, MO, USA). Analytical grade acetic acid (100\%) was obtained from Ferak Berlin (Berlin, Germany) and analytical grade formic acid (88\%) from J.T. Baker.

\subsection{Sample collection and preparation}

We collected drug-free oral fluid from nine healthy volunteers ( 4 male and 5 females, 23-25 years old), which the protocol was approved by the institutional review board (IRB) from the College of Public Health, National Taiwan University. After fasting for $20 \mathrm{~min}$, the participants were requested to spit oral fluid directly into a polypropylene tube. The sample was then stored at $-20^{\circ} \mathrm{C}$. Later, about $100 \mu \mathrm{L}$ of oral fluid was placed in a $1.5-\mathrm{mL}$ microtube (Scientific Specialties Incorporated, Lodi, CA, USA). The exact volume was calculated by weight assuming that the oral fluid density was $0.993 \mathrm{~g} / \mathrm{mL}$ [44]. The fluid was then diluted with twice the amount of distilled and deionized water (Milli-Q water, from a Millipore RiOs Water Purification System, Billerica, MA, USA) and vortexed for $30 \mathrm{~s}$. The mixture was spiked with $20 \mu \mathrm{L}$ of isotopelabeled internal standards (IS) in methanol and vortexed again for $30 \mathrm{~s}$. Considering the sensitivity using different ionization methods, the concentrations of the IS in the spiked solutions were $91.2 \mathrm{ng} / \mathrm{mL}$ for ESI and $34.2 \mathrm{ng} / \mathrm{mL}$ for APCI and APPI $(229 \mathrm{ng} / \mathrm{mL}$ of ecgonine methyl ester for APPI), which resulted in concentrations of the IS in the oral fluid at $18.2 \mathrm{ng} / \mathrm{mL}$ for ESI and at $6.84 \mathrm{ng} / \mathrm{mL}$ for APCI and APPI ( $45.8 \mathrm{ng} / \mathrm{mL}$ of ecgonine methyl ester for APPI), respectively. The samples were centrifuged for $20 \mathrm{~min}$ at $14,800 \mathrm{rpm}(16,162 \times g)$ using a bench top centrifuge (Beckman Microfuge 16, Brea, CA, USA). The supernatant was filtered with a $0.22-\mu \mathrm{m}$ PVDF syringe filter (from Millipore) and collected for analysis.

\subsection{Instrumental analysis}

Liquid chromatography was performed using an ACQUITY UPLC System (Waters, Milford, MA, USA). Analytes were separated on a Waters HSS T3 column $(100 \mathrm{~mm} \times 2.1 \mathrm{~mm}, 1.8 \mu \mathrm{m})$ at $40^{\circ} \mathrm{C}$ with a gradient elution set at a flow rate of $0.5 \mathrm{~mL} / \mathrm{min}$. The mobile phases were composed of acetonitrile $(\mathrm{A})$ and $10-\mathrm{mM}$ ammonium acetate in Milli-Q water (B) ( $\mathrm{pH}$ 6.25). The gradient started from 10\% of A for 
1. Opiates and metabolites

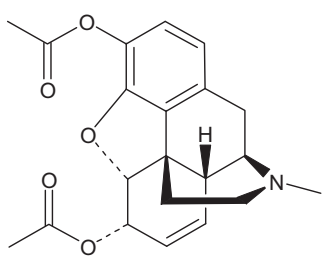

Heroin

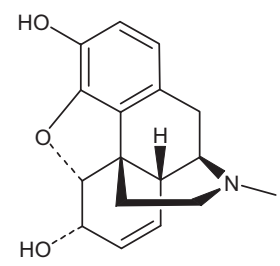

Morphine

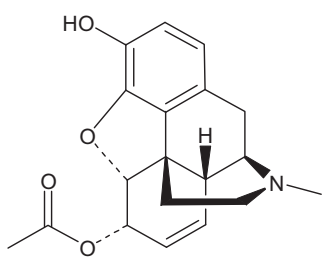

6-Acetylmorphine

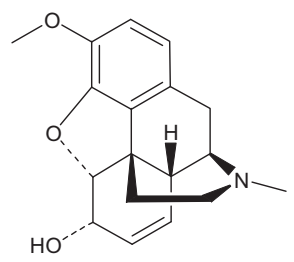

Codeine

2. Amphetamines<smiles>CNC(C)Cc1ccccc1</smiles>

Amphetamine<smiles>CC(N)Cc1ccc2c(c1)OCO2</smiles>

3,4-Methylenedioxymethamphetamine (MDMA)<smiles>CCNC(C)Cc1ccc2c(c1)OCO2</smiles>

3,4-Methylenedioxyethamphetamine (MDEA)

3. Flunitrazepam and metabolites<smiles>CN1C(=O)CN=C(c2ccccc2F)c2cc([N+](=O)[O-])ccc21</smiles>

Flunitrazepam<smiles>CN1C(=O)CN=C(c2ccccc2F)c2cc(N)ccc21</smiles>

7-Aminoflunitrazepam<smiles>O=C1CN=C(c2ccccc2F)c2cc([N+](=O)[O-])ccc2N1</smiles>

$N$-Desmethylflunitrazepam

4. Cocaine and metabolites<smiles>COC(=O)[C@H]1C[C@H]2CC[C@H](C2)N1C</smiles>

Cocaine<smiles>CCOC(=O)[C@H]1[C@@H]2CC[C@H](C2)N1COC(=O)c1ccccc1</smiles>

Cocaethylene<smiles>COC(=O)[C@H]1C2CCC(CC2)N1OC(=O)c1ccccc1</smiles>

Norcocaine<smiles>CN1[C@H]2CC[C@@H]1[C@@H](C(=O)O)[C@H](OC(=O)c1ccccc1)C2</smiles>

Benzoylecgonine

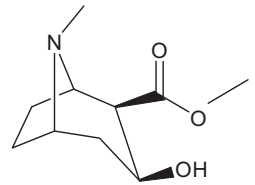

Ecgonine methyl ester

Fig. 1. The structures of the analytes.

$0.5 \mathrm{~min}$, then was increased to $60 \%$ in $4.5 \mathrm{~min}$ to elute all analytes; thereafter, acetonitrile was increased to $90 \%$ in $0.2 \mathrm{~min}$ and held for $0.5 \mathrm{~min}$ to flush the column. The mobile phase was returned to the initial composition in $0.3 \mathrm{~min}$ and the column was re-equilibrated for $1.5 \mathrm{~min}$. The total run time was $7.5 \mathrm{~min}$. The injection volume of samples was $35 \mu \mathrm{L}$. For APCI, we added a supplemental $0.5 \mathrm{~mL} / \mathrm{min}$ of $70 \% \mathrm{MeOH} / 30 \%$ Milli-Q water (v/v) post-column by a Jasco PU-
2080 Plus HPLC pump (Great Dunmow, Essex, UK) through a T connector.

Separation of analytes was also tested on a Waters BEH-HILIC column $(100 \mathrm{~mm} \times 2.1 \mathrm{~mm}, 1.7 \mu \mathrm{m})$ at $40^{\circ} \mathrm{C}$ with a gradient elution at $0.5 \mathrm{~mL} / \mathrm{min}$. The mobile phases were acetonitrile (A) and $10 \mathrm{mM}$ ammonium formate with $10 \mathrm{mM}$ formic acid in Milli-Q water (B) ( $\mathrm{pH}$ 3.41). The gradient began from $90 \%$ of $A$ for $0.5 \mathrm{~min}$, and was 
then decreased to $65 \%$ in $4.5 \mathrm{~min}$ to elute all analytes. The percentage of acetonitrile was decreased to $60 \%$ in $0.1 \mathrm{~min}$ and held for $0.4 \mathrm{~min}$ to flush the column. The mobile phase was returned to the initial composition in $0.2 \mathrm{~min}$ and the column was re-equilibrated for $2.3 \mathrm{~min}$. The total run time was $8 \mathrm{~min}$.

Analytes were detected by a Waters Quattro Premier XE triplequadrupole mass spectrometer using selected reaction monitoring (SRM) with ESI, APCI, or APPI in positive ion mode. The details of optimized cone voltage and collision energy for the monitored ion transitions and the optimized parameters of the three ionization probes are shown in Appendices A, B and C in the supplementary material. The most intense product ions (product ion I) from the most abundant precursor ions $\left([\mathrm{M}+\mathrm{H}]^{+}\right)$were used for quantitation, and the next most intense product ions (product ion II) were used for confirmation. Data acquisition was divided into five segments based on LC retention time to reduce the number of ion transitions that needed to be monitored simultaneously (3-15 ion transitions in each segment) and to maximize the dwell time of each monitored ion but maintain sufficient number of data points (>15) across the peak to integrate the area. The desolvation gas was nitrogen and the collision gas was argon with collision cell pressure $3.8 \times 10^{-3}$ mbar.

\subsection{Evaluation of matrix effects and recovery of sample preparation}

A $100-\mu \mathrm{L}$ sample of oral fluid was pretreated as Section 2.2 and then was spiked with $20 \mu \mathrm{L}$ of working solution of standards in methanol to make the spiked concentrations comparable to the middle concentrations of the calibration curve. The signal intensities of the analytes in the spiked sample was compared with the same amount of pure standards to estimate the matrix effect $(n=4)$. The calculation of ion suppression was as follows: ion suppression $=[1-(A / B)] \times 100 \%$, where $(A)$ is the peak areas of the analytes spiked after the sample pretreatment, and $(B)$ the peak areas of the analyte standards.

Recoveries of the sample preparation were evaluated $(n=5)$ by spiking known amounts of analytes into diluted oral fluid blank then vortexed before centrifugation. The signal intensities of the analytes were then compared with the intensities of the same amount of standards in the post-spiked samples.

Post-column split (5:1) was performed using a QuickSplit flow splitter (ASI, El Sobrante, CA, USA), which was used to reduce the infusion flow rate into the mass spectrometer. This would enhance the ionization efficiency of analytes at ESI. We then compared the responses of split and splitless analytes.

\subsection{Quantitation and data analysis}

For ESI, calibration was prepared at the concentrations of native drugs ranging from 0.25 to $1000 \mathrm{ng} / \mathrm{mL}$ in methanol with $50 \mathrm{ng} / \mathrm{mL}$ isotope-labeled IS. The 17 illicit drugs were categorized into three groups based on their instrumental sensitivity. 6-Acethylmorphine, methamphetamine, flunitrazepam, benzoylecgonine, and cocaethylene were classified to the first group with the lowest instrumental quantitation limits (IQLs). Heroin, morphine, codeine, MDMA, MDEA, 7-aminoflunitrazepam, $\mathrm{N}$-desmethylflunitrazepam, cocaine, norcocaine were classified as the second group; and the remaining analytes (amphetamine, MDA, ecgonine methyl ester) made up the third group, had the lowest responses.

The instrumental sensitivity of analytes using APCI and APPI were similar to each other, so we used the same calibration range for quantitation. Calibration was prepared at concentrations of native drugs ranging from 0.1 to $500 \mathrm{ng} / \mathrm{mL}$ in methanol with $15 \mathrm{ng} / \mathrm{mL}$ isotope-labeled IS. Similarly, the seventeen illicit drugs were categorized into three groups. MDMA, 7-aminoflunitrazepam, cocaine, norcocaine, benzoylecgonine, and cocaethylene made up the first group, the one with the lowest IQLs. 6-Acethylmorphine, heroin, MDEA, MDA, and flunitrazepam made up the second group, and the rest (morphine, codeine, amphetamine, methamphetamine, and $\mathrm{N}$-desmethylflunitrazepam) the third group. Because ecgonine methyl ester was the least sensitive analyte in oral fluid, the calibration range we used for it was 2 to $1000 \mathrm{ng} / \mathrm{mL}$ in methanol with $100 \mathrm{ng} / \mathrm{mL}$ of the isotope-labeled internal standard.

Isotope-labeled IS were spiked before the sample preparation to measure the concentration of each analyte in the oral fluid. Each native analyte had its individual internal standard except for norcocaine. Because the chemical structure of norcocaine and benzoylecgonine are similar, we used benzoylecgonine- $\mathrm{D}_{8}$ as the internal standard for norcocaine. To reduce the number of monitored ion transitions, we only monitored the product ion I on the IS in our analysis, though the information on confirmatory ions is shown in Appendix A in the supplementary material. The differences in retention time between each native analyte and its internal standard had to be less than $\pm 2.5 \%$ [45].

Linear regression analysis was used in our calibrations with a weighting factor of $1 / \chi$, which provided better accuracy and precision for quantitation than not using weighting factors or using a weighting factor of $1 / \chi^{2}$. Each standard curve was based on at least six different concentrations; the square correlation coefficients $\left(r^{2}\right)$ were larger than 0.995 and most of the linear ranges were larger than two orders of magnitude (details are shown in Appendix D in the supplementary material). The $X$-axis of a calibration curve was calculated as the ratio of the concentration of each native analyte to fixed concentrations of IS, and the $Y$-axis was defined as the peak area ratio of native analytes to their internal standards. The quantitation of native analytes was normalized to the IS.

The accuracies and precisions of the method were assessed at three spiked levels (low, medium and high) in oral fluid ( $n=4$ at each level). The spiked amount in the oral fluid at each level was based on the instrumental sensitivity of the analytes. Precision was also examined by repeated injections $(n=3)$ of spiked samples at the low and the high levels on the same day (intra-day) and on different days (inter-day).

Masslynx 4.1 (Waters) was used for the acquisition of data, which was exported to Microsoft Excel 2007 for further data processing.

The instrumental detection limit (IDL) was defined as the lowest mass of an analyte to produce a signal-to-noise ratio $(\mathrm{S} / \mathrm{N})$ of the quantitative ion equal to three and the IQL was defined having an $\mathrm{S} / \mathrm{N}$ ratio equal to 10 . For better identification, the LOD of the method was defined as the concentration of an analyte in oral fluid with an $\mathrm{S} / \mathrm{N}$ ratio equaling 3 at the confirmatory ion and the LOQ was that equaling 10 at the quantitative ion, respectively; the LOD and LOQ were calculated using the $\mathrm{S} / \mathrm{N}$ ratios in the oral fluid samples that were spiked at the low levels for evaluating the method accuracy and precision. In case the LOQ was lower than the LOD under the above definitions, we reported the LOQ as the same value of LOD.

\subsection{Quality assurance and quality control}

To minimize the adsorption of the analytes on glass surface, all glassware was silanized with a solution of 7\% DMDCS in toluene. The silanized autosampler vials and inserts were purchased from Waters.

There was a reagent blank and an oral fluid blank for each batch of sample to check for lab contamination and endogenous levels of each analyte. We observed no lab contamination or detectable levels of the analytes in the oral fluid we collected for the experiments. 


\section{Results and discussion}

\subsection{Chromatography}

Acetonitrile as the organic mobile phase provided better separation and sharper analyte peaks than methanol on the high strength silica (HSS) T3 column. Simões et al. also chose acetonitrile as the organic mobile phase using a Waters Atlantis T3 column, which has the same packing material but in a larger particle size than the HSS T3, to separate 24 illicit drugs and medicines in oral fluid [46]. Similarly, two other studies have also used acetonitrile to analyze illicit drugs in oral fluid with C18 columns [33,47]. Badawi et al., on the other hand, used the same UHPLC column as ours but reported methanol as their organic mobile phase [48]. We assessed the use of both ammonium formate and ammonium acetate ( 5 and $10 \mathrm{mM}$ ) as aqueous mobile phases, and that peak tailing was least with the use of $10 \mathrm{mM}$ of ammonium acetate, and adding acetic acid achieved no improvement in peak shapes (Fig. 2). All analytes were eluted within $5 \mathrm{~min}$. The capacity factor $\left(k^{\prime}\right)$ of most analytes ranged between 2.4 (morphine, retention time $1.70 \mathrm{~min}$ ) to 8.4 (flunitrazepam, retention time $4.71 \mathrm{~min}$ ) except for ecgonine methyl ester (two peaks, retention time 0.53 and $0.73 \mathrm{~min} ; k^{\prime} 0.06$ and 0.46). The peaks were $4.2-7.2 \mathrm{~s}$ wide. Compared with the gradient used by Badawi et al., the one we used in our study was much simpler and had a retention time of about half that of theirs on the same analytes [48].

Hydrophilic interaction chromatography (HILIC) provided good detection sensitivity on ESI. The IDLs of thirteen analytes ranged from 0.13 to $0.48 \mathrm{pg}$. For heroin, flunitrazepam, benzoylecgonine they were around $0.7 \mathrm{pg}$ and for morphine $1.3 \mathrm{pg}$. The BEH-HILIC column did not, however, retain flunitrazepam, 7aminoflunitrazepam, or $N$-desmethylflunitrazepam well $\left(k^{\prime}\right.$ ranged from 0.16 to 0.3 ), though several compositions and gradients of mobile phases were tested. Moreover, after sample preparation, specimens consisted mostly of water, which is a strong solvent to a HILIC column and prevents the analysis from use of a large-volume injection. Consequently, we did not further investigate the suitability of this column for the analysis, even though the IDLs were impressive.

\subsection{Matrix effects and sample preparation}

We simplified the sample preparation of oral fluid by diluting the sample with twice amount of Milli-Q water followed by 20-min centrifugation, which significantly reduced the viscosity of oral fluid and produced lower ion suppression in ESI source than other procedures we tested with different centrifugation times and dilution volumes (details were not shown). The recoveries of the analytes during the sample preparation were $81-108 \%$ (Table 1) and the ion suppression of most analytes in ESI ranged from 28 to $78 \%$ (Table 2). The ion enhancement for amphetamine, MDA and 7 -aminoflunitrazepam ranged from 5.1 to $28.1 \%$ (Table 2). After the dilution, the sample was much easier to handle and the procedure was organic-solvent free. This makes it especially useful in the preparation of samples from amphetamine abusers whose symptomatic "dry mouth" limits the amount of oral fluid that can be collected [30]. Furthermore, the step could be performed on as many as 24 specimens at a time, dramatically increasing sample throughput.

Because ESI response is considered concentration-dependent and a low flow may improve ionization efficiency, we tested post-column flow split (5:1). This approach did not reduce matrix effects. The ion suppression of most analytes ranged from 46 to $80 \%$. Ion enhancement was observed on amphetamine (53\%) and 7-aminoflunitrazepam (12\%). The peak widths with flow splitting were $20-30 \%$ broader than with those that
Table 1

The recovery of sample preparation $(n=5)$.

\begin{tabular}{lc}
\hline Compound & Mean \pm SD $(\%)$ \\
\hline Opiates and metabolites & \\
Heroin & $98.4 \pm 5.61 \%$ \\
Morphine & $98.0 \pm 7.87 \%$ \\
6-Acetylmorphine & $88.4 \pm 9.40 \%$ \\
Codeine & $108 \pm 8.15 \%$ \\
Amphetamines & \\
Amphetamine & $97.5 \pm 5.16 \%$ \\
Methamphetamine & $96.3 \pm 5.27 \%$ \\
MDMA & $96.3 \pm 5.14 \%$ \\
MDA & $92.7 \pm 2.68 \%$ \\
MDEA & $90.8 \pm 8.56 \%$ \\
Flunitrazepam and metabolites & \\
Flunitrazepam & $81.1 \pm 3.37 \%$ \\
7-Aminoflunitrazepam & $96.2 \pm 9.43 \%$ \\
-Desmethylflunitrazepam & $80.7 \pm 4.37 \%$ \\
Cocaine and metabolites & \\
Cocaine & $87.6 \pm 5.98 \% \mathrm{a}$ \\
Norcocaine & $90.0 \pm 6.22 \%$ \\
Benzoylecgonine & $96.2 \pm 7.09 \%$ \\
Ecgonine methyl ester & $93.8 \pm 5.47 \%$ \\
Cocaethylene & \\
\hline a $n=4.8 \pm 17.9 \%{ }^{\mathrm{a}}$ \\
\hline
\end{tabular}

were not split because of a much lower post-column flow rate.

The sample preparation used in this study was much simpler than that used for SPE and LLE but the ion suppression on ESI was similar to most other studies using LC-MS/MS-ESI. Wood et al., using SPE to extract $250-\mu \mathrm{L}$ oral fluids, reported minor matrix effects (up to 13\%) for nine illicit drugs [28]. Using SPE to extract drugs from oral fluids as well, Concheiro et al. and Badawi et al. reported slightly higher ion suppression (up to 35-37\%) [33,48], and Mortier et al. reported ion suppression ranges from 21 to 55\% [29]; in contrast, Fritch et al. observed ion enhancement on most analytes (up to 57\%) [31]. Using LLE to extract amphetamines, cocaine, flunitrazepam and codeine from oral fluid, Oiestad et al. reported ion suppression to be above 90\% [38]. Sergi et al., using rapid protein precipitation of $150-\mu \mathrm{L}$ oral fluid for determining thirteen illicit

Table 2

The ion suppression on ESI+, APCI+, and APPI+ $(n=4)$.

\begin{tabular}{|c|c|c|c|}
\hline \multirow[t]{2}{*}{ Compound } & \multicolumn{3}{|l|}{ Mean \pm SD } \\
\hline & ESI & APCI & APPI \\
\hline \multicolumn{4}{|l|}{ Opiates and metabolites } \\
\hline Heroin & $36.6 \pm 6.2 \%$ & $48.3 \pm 4.2 \%$ & $76.2 \pm 3.6 \%$ \\
\hline Morphine & $77.8 \pm 1.6 \%$ & $96.9 \pm 0.59 \%$ & $99.6 \pm 0.09 \%$ \\
\hline 6-Acetylmorphine & $65.3 \pm 4.6 \%$ & $59.8 \pm 5.3 \%$ & $82.9 \pm 2.3 \%$ \\
\hline Codeine & $72.4 \pm 1.7 \%$ & $76.2 \pm 2.2 \%$ & $86.7 \pm 2.0 \%$ \\
\hline \multicolumn{4}{|l|}{ Amphetamines } \\
\hline Amphetamine & $-28.7 \pm 9.3 \%^{\mathrm{a}}$ & $53.1 \pm 2.4 \%$ & $93.6 \pm 1.1 \%$ \\
\hline Methamphetamine & $6.90 \pm 3.1 \%$ & $57.9 \pm 3.0 \%$ & $93.7 \pm 0.71 \%$ \\
\hline MDMA & $33.3 \pm 4.0 \%$ & $72.2 \pm 2.4 \%$ & $94.4 \pm 1.3 \%$ \\
\hline MDA & $-27.6 \pm 7.9 \%^{\mathrm{a}}$ & $54.2 \pm 1.0 \%$ & $92.5 \pm 2.0 \%$ \\
\hline MDEA & $56.1 \pm 2.2 \%$ & $81.2 \pm 1.2 \%$ & $96.3 \pm 0.40 \%$ \\
\hline \multicolumn{4}{|l|}{ Flunitrazepam and metabolites } \\
\hline Flunitrazepam & $50.3 \pm 4.8 \%$ & $55.4 \pm 8.5 \%$ & $79.9 \pm 5.0 \%$ \\
\hline 7-Aminoflunitrazepam & $-5.10 \pm 8.0 \% \mathrm{a}$ & $61.5 \pm 3.8 \%$ & $87.2 \pm 1.2 \%$ \\
\hline$N$-Desmethylflunitrazepam & $18.7 \pm 7.3 \%$ & $45.4 \pm 9.1 \%$ & $74.4 \pm 4.9 \%$ \\
\hline \multicolumn{4}{|l|}{ Cocaine and metabolites } \\
\hline Cocaine & $92.0 \pm 5.5 \%$ & $89.0 \pm 6.5 \%$ & $93.7 \pm 3.4 \%$ \\
\hline Norcocaine & $47.5 \pm 4.8 \%$ & $61.7 \pm 4.0 \%$ & $85.4 \pm 2.0 \%$ \\
\hline Benzoylecgonine & $28.0 \pm 3.6 \%$ & $46.8 \pm 3.2 \%$ & $90.1 \pm 1.7 \%$ \\
\hline Ecgonine methyl ester & $55.1 \pm 2.0 \%$ & $99.8 \pm 0.001 \%$ & $99.98 \pm 0.004 \%$ \\
\hline Cocaethylene & $98.0 \pm 2.7 \%$ & $99.3 \pm 0.33 \%$ & $99.5 \pm 0.25 \%$ \\
\hline
\end{tabular}

a Ion enhancement. 

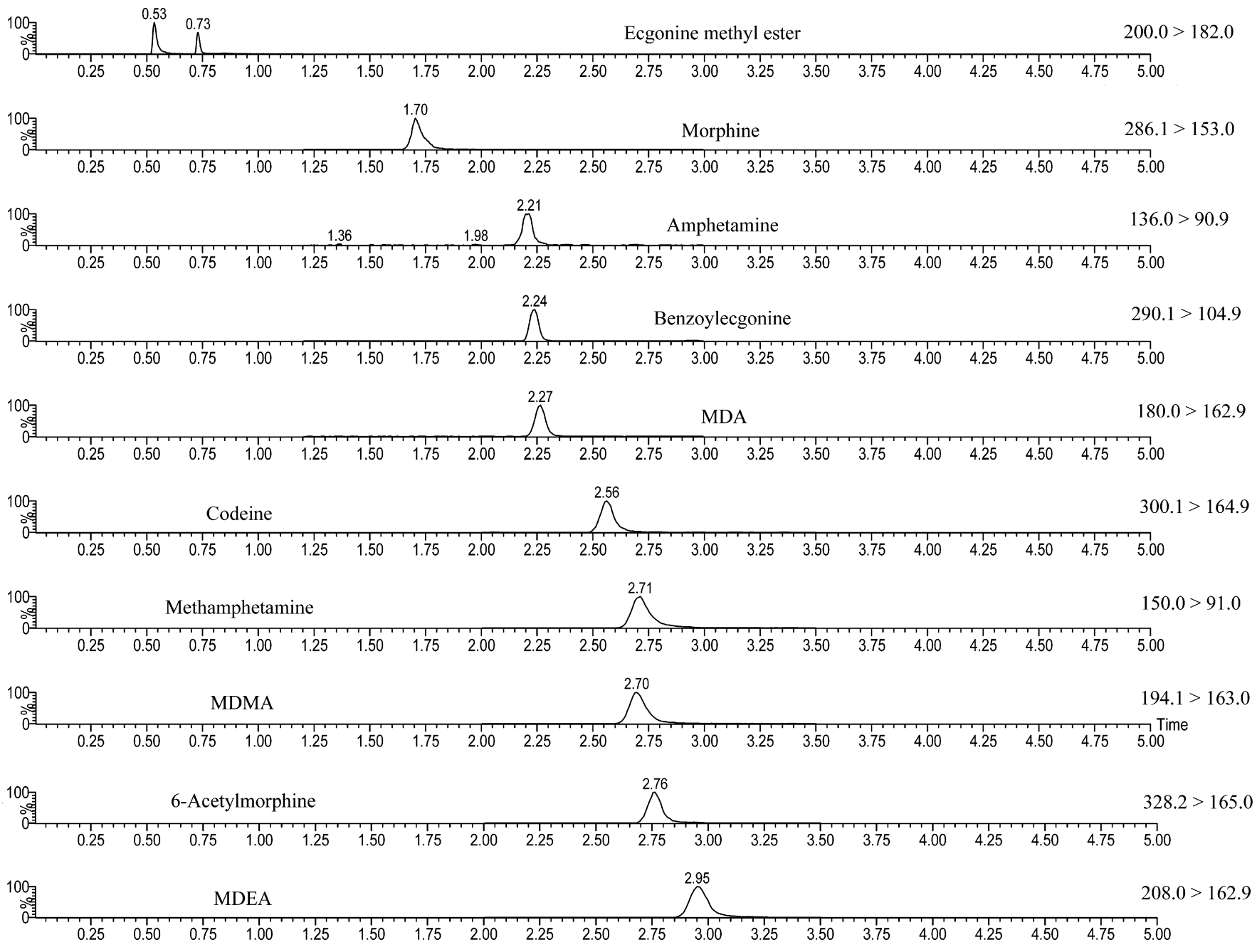

\begin{tabular}{|c|c|c|c|c|c|c|c|c|c|c|c|c|c|c|c|c|c|c|c|}
\hline 월 & & mino & anitr & epam & & & & & & & & $\bigwedge^{3.27}$ & & & & & & & $284.0>134.9$ \\
\hline 0.25 & 0.50 & 0.75 & 1.00 & 1.25 & 1.50 & 1.75 & 2.00 & 2.25 & 2.50 & 2.75 & 3.00 & 3.25 & 3.50 & 3.75 & 4.00 & 4.25 & 4.50 & 4.75 & 5.00 \\
\hline
\end{tabular}
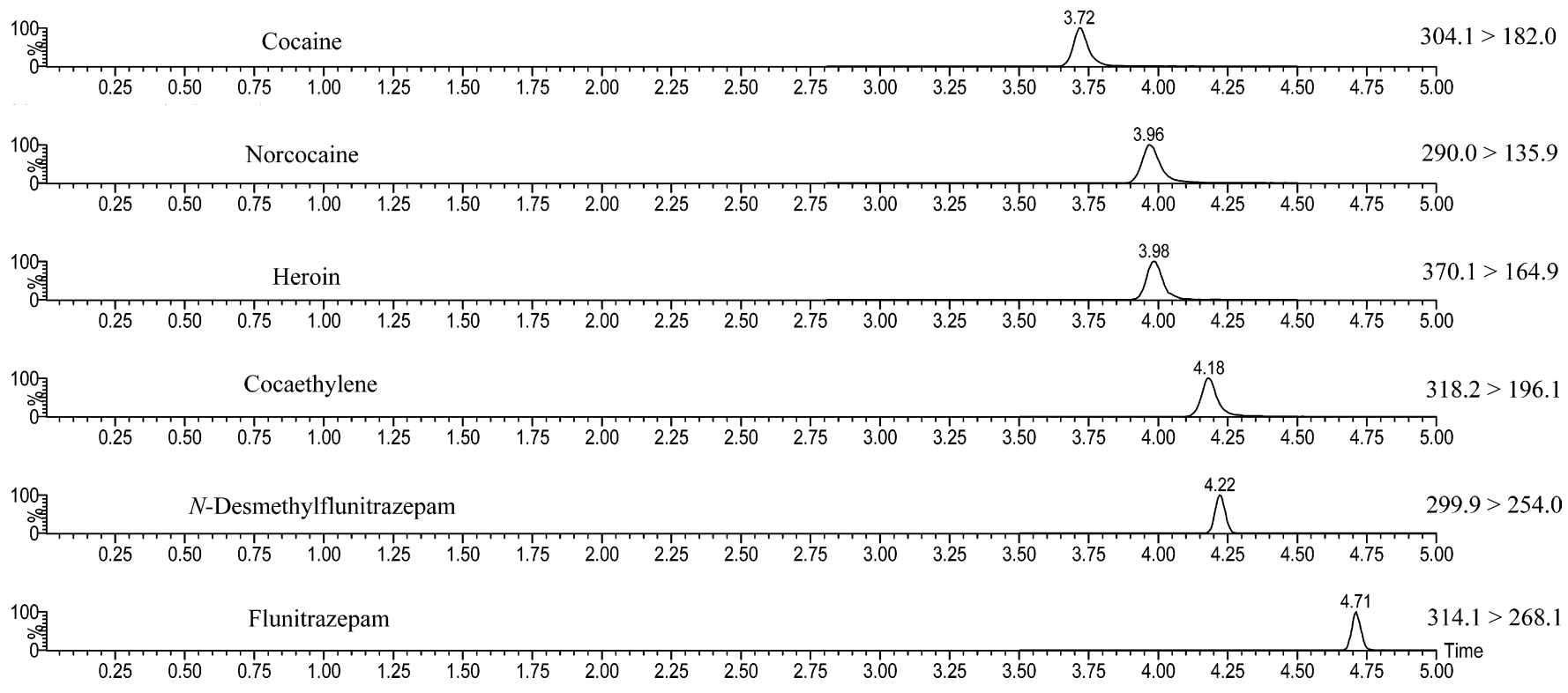

Fig. 2. The chromatogram of 17 illicit drugs on a HSS-T3 column $(0.1 \mathrm{ng} / \mu \mathrm{L}, 4-\mu \mathrm{L}$ injection on ESI+). 
Table 3

The limits of detection and limits of quantitation of the method on ESI+, APCI+, and APPI+ $(n=4)$.

\begin{tabular}{|c|c|c|c|c|c|c|}
\hline \multirow[t]{2}{*}{ Compound } & \multicolumn{2}{|l|}{ ESI+ } & \multicolumn{2}{|l|}{ APCI+ } & \multicolumn{2}{|l|}{ APPI+ } \\
\hline & $\begin{array}{l}\mathrm{LOD}(\mathrm{ng} / \mathrm{mL})^{\mathrm{a}} \\
\text { Mean } \pm \mathrm{SD}\end{array}$ & $\begin{array}{l}\mathrm{LOQ}(\mathrm{ng} / \mathrm{mL})^{\mathrm{b}} \\
\text { Mean } \pm \mathrm{SD}\end{array}$ & $\begin{array}{l}\mathrm{LOD}(\mathrm{ng} / \mathrm{mL}) \\
\text { Mean } \pm \mathrm{SD}\end{array}$ & $\begin{array}{l}\mathrm{LOQ}(\mathrm{ng} / \mathrm{mL}) \\
\text { Mean } \pm \mathrm{SD}\end{array}$ & $\begin{array}{l}\mathrm{LOD}(\mathrm{ng} / \mathrm{mL}) \\
\text { Mean } \pm \text { SD }\end{array}$ & $\begin{array}{l}\mathrm{LOQ}(\mathrm{ng} / \mathrm{mL}) \\
\text { Mean } \pm \mathrm{SD}\end{array}$ \\
\hline \multicolumn{7}{|l|}{ Opiates and metabolites } \\
\hline Heroin & $0.26 \pm 0.03$ & $0.87 \pm 0.10$ & $0.67 \pm 0.08$ & $0.67 \pm 0.08$ & $0.082 \pm 0.016$ & $0.21 \pm 0.03$ \\
\hline Morphine & $0.95 \pm 0.08$ & $1.92 \pm 0.36$ & $0.49 \pm 0.19$ & $0.69 \pm 0.03$ & $2.08 \pm 0.38$ & $2.08 \pm 0.38$ \\
\hline 6-Acetylmorphine & $1.70 \pm 0.57$ & $1.70 \pm 0.57$ & $0.29 \pm 0.03$ & $0.29 \pm 0.03$ & $0.27 \pm 0.10$ & $0.27 \pm 0.10$ \\
\hline Codeine & $0.39 \pm 0.01$ & $0.51 \pm 0.10$ & $0.13 \pm 0.04$ & $0.43 \pm 0.07$ & $0.24 \pm 0.04$ & $0.24 \pm 0.04$ \\
\hline \multicolumn{7}{|l|}{ Amphetamines } \\
\hline Amphetamine & $4.72 \pm 0.58$ & $4.72 \pm 0.58$ & $7.25 \pm 0.79$ & $8.71 \pm 0.90$ & $7.80 \pm 0.99$ & $10.3 \pm 1.20$ \\
\hline Methamphetamine & $0.34 \pm 0.05$ & $0.87 \pm 0.12$ & $0.35 \pm 0.08$ & $0.74 \pm 0.11$ & $0.16 \pm 0.04$ & $0.43 \pm 0.05$ \\
\hline MDMA & $0.22 \pm 0.05$ & $0.56 \pm 0.08$ & $0.19 \pm 0.03$ & $0.19 \pm 0.03$ & $0.091 \pm 0.014$ & $0.17 \pm 0.03$ \\
\hline MDA & $0.15 \pm 0.03$ & $0.29 \pm 0.04$ & $0.21 \pm 0.04$ & $0.64 \pm 0.08$ & $0.27 \pm 0.06$ & $0.27 \pm 0.06$ \\
\hline MDEA & $0.20 \pm 0.05$ & $0.38 \pm 0.03$ & $2.20 \pm 0.52$ & $2.20 \pm 0.52$ & $0.11 \pm 0.03$ & $0.27 \pm 0.03$ \\
\hline \multicolumn{7}{|l|}{ Flunitrazepam and metabolites } \\
\hline Flunitrazepam & $0.17 \pm 0.06$ & $0.24 \pm 0.02$ & $0.08 \pm 0.02$ & $0.11 \pm 0.01$ & $0.072 \pm 0.013$ & $0.094 \pm 0.003$ \\
\hline 7-Aminoflunitrazepam & $0.19 \pm 0.06$ & $0.49 \pm 0.07$ & $0.20 \pm 0.02$ & $0.20 \pm 0.02$ & $0.13 \pm 0.02$ & $0.13 \pm 0.02$ \\
\hline$N$ - Desmethylflunitrazepam & $0.16 \pm 0.03$ & $0.24 \pm 0.03$ & $0.19 \pm 0.02$ & $0.19 \pm 0.02$ & $0.12 \pm 0.02$ & $0.12 \pm 0.01$ \\
\hline \multicolumn{7}{|l|}{ Cocaine and metabolites } \\
\hline Cocaine & $0.18 \pm 0.03$ & $0.48 \pm 0.07$ & $0.13 \pm 0.02$ & $0.13 \pm 0.02$ & $0.44 \pm 0.10$ & $0.44 \pm 0.10$ \\
\hline Norcocaine & $0.15 \pm 0.03$ & $0.20 \pm 0.03$ & $0.018 \pm 0.002$ & $0.082 \pm 0.010$ & $0.016 \pm 0.002$ & $0.071 \pm 0.005$ \\
\hline Benzoylecgonine & $0.04 \pm 0.01$ & $0.11 \pm 0.02$ & $0.009 \pm 0.002$ & $0.034 \pm 0.005$ & $0.020 \pm 0.005$ & $0.048 \pm 0.002$ \\
\hline Ecgonine methyl ester & $1.32 \pm 0.29$ & $2.76 \pm 0.45$ & $5.31 \pm 0.62$ & $14.4 \pm 2.85$ & $6.05 \pm 0.85$ & $19.4 \pm 0.43$ \\
\hline Cocaethylene & $0.49 \pm 0.11$ & $0.53 \pm 0.07$ & $0.69 \pm 0.11$ & $0.69 \pm 0.11$ & $0.88 \pm 0.20$ & $0.88 \pm 0.20$ \\
\hline
\end{tabular}

a Limit of detection (LOD): $\mathrm{S} / \mathrm{N}=3: 1$

b Limit of quantitation (LOQ): $\mathrm{S} / \mathrm{N}=10: 1$.

drugs, found that the slope of calibration curve in the matrices was at most $20 \%$ lower than that in solvents [47].

ESI was equally or less susceptible to matrix effects than APCI and APPI in this study. The ion suppression ranged from 45 to $89 \%$ and from 74 to $96 \%$ on APCI and APPI, respectively (Table 2). We found higher ion suppression when studying morphine, cocaine, ecgonine methyl ester and cocaethylene than when studying other analytes (Table 2). APCI and APPI probes evaporate inlet solutions and ionize analytes via gas-phase chemistry; consequently, they are less affected than ESI by macromolecules in samples that are not evaporated. Oral fluids may contain many salts and small molecules partitioned from plasma or nasal pharynx rather than macromolecules, which can lead to an increase in ion suppression on APCI and APPI [49,50].

\subsection{Sensitivity and method validation}

With regard to on-column detection limits, APPI was more sensitive than APCI and ESI, though our analytes are polar. Except for morphine and amphetamine, the IDLs of the analytes on APPI were lower than $0.5 \mathrm{pg}$, and their IQLs mostly under $1 \mathrm{pg}$ (details are shown in Appendix E in the supplementary material). Except for heroin and amphetamine, the IDLs of the analytes on APCI were lower than $0.9 \mathrm{pg}$. ESI was the least sensitive, with only eight of the seventeen analytes having IDLs under $0.5 \mathrm{pg}$ and five with over $1 \mathrm{pg}$. APPI was 19 times more sensitive than ESI in its detection of MDMA, and 11, 15, and 37 times more sensitive in its detection of MDA, cocaine, and ecgonine methyl ester. APPI was 6 times more sensitive for heroin than $\mathrm{APCI}$, and 3, 4, 3, 3, and 12 times more sensitive in its detection of MDMA, MDA, flunitrazepam, norcocaine, and benzoylecgonine. Comparing APCI with ESI, APCI was 7 times more sensitive in its detection of MDMA than ESI, and 13 and 9 times more sensitive in its detection of cocaine and ecgonine methyl ester. Cai et al., comparing the ionization efficiencies of ESI, APCI, and APPI on 86 compounds, including wide ranges of polarities and chemical structures [41], found that the overall ionization efficiency of APPI was greater than the other two probes, a finding consistent with those of this study.
On APPI, in contrast to theories [51], acetonitrile as the organic mobile phase offered better analyte responses than methanol, and most analytes gave the strongest signal intensity when we did not add dopant. We compared the analyte signals of direct APPI with those of dopant-assisted APPI by post-column addition of $5 \%$ or $10 \%$ toluene. Signals of MDA, methamphetamine, MDEA, cocaethylene, heroin, 6-acetylmorphine, benzoylecgonine, $\mathrm{N}$ desmethylflunitrazepam, amphetamine, and flunitrazepam were the highest with direct APPI. The signals for the remaining analytes with direct APPI were similar to those with the APPI with dopant added. These findings might be explained by the fact that the analytes possess phenyl or ketone structures and amine groups, which result in lower ionization energies and higher proton affinities, eliminating the need for dopant to enhance the reactions of photoionization. The addition of toluene would quench the direct APPI by absorbing available photons, competing for protons, or neutralizing radical cations and ionized analytes.

APCI and APPI provided similar or better sensitivity (1-5 times) for most analytes in oral fluid than ESI, except for amphetamine and ecgonine methyl ester (Table 3). On ESI, most analytes had LODs ranging from 0.03 to $0.95 \mathrm{ng} / \mathrm{mL}$. The detection of 6acetylmorphine, amphetamine and ecgonine methyl ester was less sensitive with LODs ranging from 1.3 to $4.7 \mathrm{ng} / \mathrm{mL}$. The LODs of most analytes on APCI and APPI ranged from 0.01 to $0.88 \mathrm{ng} / \mathrm{mL}$. As was found with ESI, the detection of amphetamine (LOD 7.3-7.8 ng/mL) and ecgonine methyl ester (LOD 5.3-6.1 ng/mL) was less sensitive on APCI and APPI, compared to the other analytes (Table 3). The LOQs of most analytes in this study ranged from 0.11 to $1.9 \mathrm{ng} / \mathrm{mL}$, from 0.02 to $2.2 \mathrm{ng} / \mathrm{mL}$ and from 0.02 to $2.1 \mathrm{ng} / \mathrm{mL}$ on ESI, APCI and APPI, respectively (Table 3 ).

Although we only used $100-\mu$ L oral fluid with a simple pretreatment, the sensitivity of our method was comparable or better than those reported by previous studies. Badawi et al. used exactly the same model of UHPLC-MS/MS and exactly the same LC column with those of our study, but pre-treated $200 \mathrm{mg}$ of oral fluid with SPE; however, our LOQs on ESI were equal or as much as ten-fold lower than the ones they reported [48]. Mortier et al., processing 200$\mu \mathrm{L}$ oral fluid with SPE to detect opiates, amphetamines, cocaine 
Table 4

The accuracy and precision of spiked samples on ESI+ $(n=4)$.

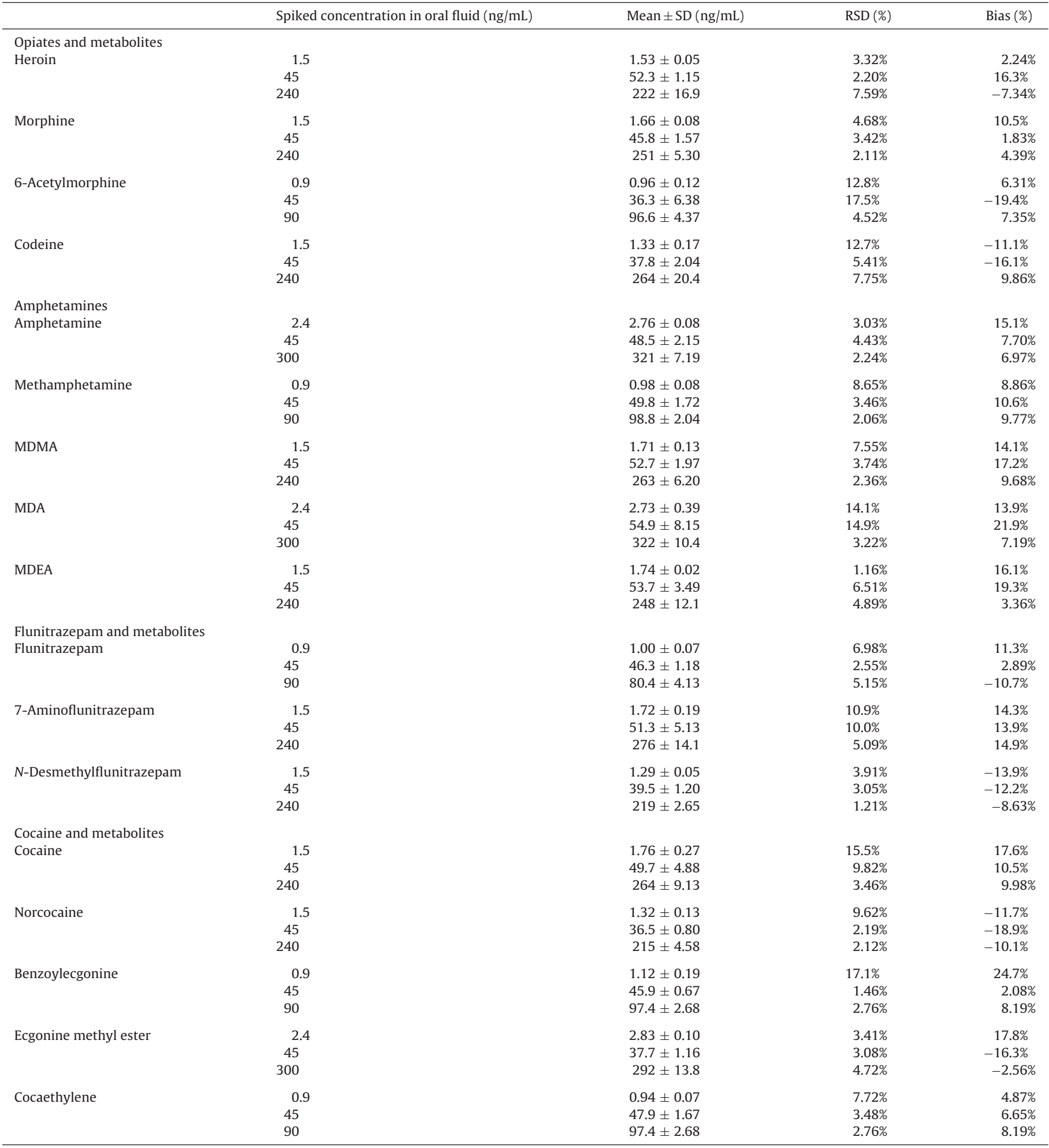

and benzoylecgonine using a quadrupole time-of-flight MS and ESI, reported the LODs to range from 0.22 to $1.07 \mathrm{ng} / \mathrm{mL}$ and all the LOQs to be $2 \mathrm{ng} / \mathrm{mL}$ [29]. Wylie et al. pretreating $1-\mathrm{mL}$ oral fluid with SPE and using an ion-trap MS with ESI to detect 49 licit and illicit drugs, reported LODs to range from 0.3 to $3.4 \mathrm{ng} / \mathrm{mL}$ and LOQs to range from 1.0 to $11.4 \mathrm{ng} / \mathrm{mL}$ [7]. In their study, two injections were needed per sample to get sufficient data points across the peak because of the large number of ion transitions that needed monitoring. Dams et al., handling $200-\mu \mathrm{L}$ oral fluid with protein precipitation to determine 27 compounds using an ion trap MS with APCI [39], reported the LODs and LOQs to be 0.5 and $1.0 \mathrm{ng} / \mathrm{mL}$ for morphine, codeine, 6-acetylmorphine, heroin, cocaine, norcocaine and cocaethylene. They were 0.25 and $0.5 \mathrm{ng} / \mathrm{mL}$ for benzoylecgonine. Like our results, Dams et al. reported a higher LOD and LOQ for the detection on ecgonine methyl ester than other analytes, which were 5.0 and $10.0 \mathrm{ng} / \mathrm{mL}$ [39]. 
Table 5

The accuracy and precision of spiked samples on APCI+ and APPI+ $(n=4)$.

\begin{tabular}{|c|c|c|c|c|c|c|c|}
\hline & \multirow{2}{*}{$\begin{array}{l}\text { Spiked concentration } \\
\text { in oral fluid }(\mathrm{ng} / \mathrm{mL})\end{array}$} & \multicolumn{3}{|l|}{$\mathrm{APCI}$} & \multicolumn{3}{|l|}{ APPI } \\
\hline & & Mean $\pm \mathrm{SD}(\mathrm{ng} / \mathrm{mL})$ & RSD (\%) & Bias (\%) & Mean $\pm \mathrm{SD}(\mathrm{ng} / \mathrm{mL})$ & RSD (\%) & Bias (\%) \\
\hline $\begin{array}{l}\text { Opiates and metabolites } \\
\text { Heroin }\end{array}$ & $\begin{array}{l}0.75 \\
10.5 \\
45.0\end{array}$ & $\begin{array}{l}0.78 \pm 0.03 \\
9.68 \pm 0.14 \\
43.6 \pm 3.12\end{array}$ & $\begin{array}{l}3.70 \% \\
4.35 \% \\
7.17 \%\end{array}$ & $\begin{array}{r}3.99 \% \\
-7.81 \% \\
-3.21 \%\end{array}$ & $\begin{array}{l}0.78 \pm 0.04 \\
10.9 \pm 0.98 \\
48.1 \pm 5.36\end{array}$ & $\begin{array}{l}5.69 \% \\
8.97 \% \\
10.7 \%\end{array}$ & $\begin{array}{l}3.37 \% \\
3.65 \% \\
7.12 \%\end{array}$ \\
\hline Morphine & $\begin{array}{l}0.90 \\
10.5 \\
150\end{array}$ & $\begin{array}{l}0.96 \pm 0.06 \\
10.7 \pm 0.82 \\
165 \pm 10.3\end{array}$ & $\begin{array}{l}5.84 \% \\
7.64 \% \\
6.23 \%\end{array}$ & $\begin{array}{c}7.15 \% \\
1.90 \% \\
10.5 \%\end{array}$ & $\begin{array}{l}0.93 \pm 0.04 \\
10.7 \pm 0.37 \\
159 \pm 14.9\end{array}$ & $\begin{array}{l}4.54 \% \\
3.44 \% \\
9.37 \%\end{array}$ & $\begin{array}{l}3.82 \% \\
2.17 \% \\
5.80 \%\end{array}$ \\
\hline 6-Acetylmorphine & $\begin{array}{l}0.75 \\
10.5 \\
45.0\end{array}$ & $\begin{array}{l}0.71 \pm 0.06 \\
9.76 \pm 0.24 \\
41.9 \pm 4.79\end{array}$ & $\begin{array}{l}8.98 \% \\
2.46 \% \\
11.5 \%\end{array}$ & $\begin{array}{l}-5.60 \% \\
-7.05 \% \\
-7.00 \%\end{array}$ & $\begin{array}{l}- \\
10.3 \pm 0.12 \\
42.1 \pm 3.16\end{array}$ & $\begin{array}{l}- \\
1.20 \% \\
7.49 \%\end{array}$ & $\begin{array}{l}- \\
-2.24 \% \\
-6.41 \%\end{array}$ \\
\hline Codeine & $\begin{aligned} & 0.90 \\
& 10.5 \\
& 150\end{aligned}$ & $\begin{array}{l}1.01 \pm 0.09 \\
11.3 \pm 0.17 \\
162 \pm 12.9\end{array}$ & $\begin{array}{l}8.84 \% \\
1.50 \% \\
7.96 \%\end{array}$ & $\begin{array}{c}11.8 \% \\
7.62 \% \\
8.31 \%\end{array}$ & $\begin{array}{l}1.01 \pm 0.16 \\
11.4 \pm 1.04 \\
176 \pm 21.4\end{array}$ & $\begin{array}{c}15.8 \% \\
9.12 \% \\
12.2 \%\end{array}$ & $\begin{array}{c}12.2 \% \\
9.52 \% \\
17.4 \%\end{array}$ \\
\hline $\begin{array}{l}\text { Amphetamines } \\
\text { Amphetamine }\end{array}$ & $\begin{array}{c}0.90 \\
10.5 \\
150\end{array}$ & $\begin{array}{l}- \\
11.6 \pm 0.89 \\
177 \pm 25.4\end{array}$ & $\begin{array}{c}- \\
7.64 \% \\
14.4 \%\end{array}$ & $\begin{array}{c}- \\
10.3 \% \\
17.8 \%\end{array}$ & $\begin{array}{l}1.05 \pm 0.12 \\
11.6 \pm 1.59 \\
171 \pm 23.1\end{array}$ & $\begin{array}{l}11.4 \% \\
13.7 \% \\
13.6 \%\end{array}$ & $\begin{array}{l}16.7 \% \\
10.2 \% \\
13.5 \%\end{array}$ \\
\hline Methamphetamine & $\begin{array}{l}0.90 \\
10.5 \\
150\end{array}$ & $\begin{array}{l}0.97 \pm 0.13 \\
10.9 \pm 0.85 \\
158 \pm 9.16\end{array}$ & $\begin{array}{l}1.00 \% \\
7.82 \% \\
5.78 \%\end{array}$ & $\begin{array}{l}8.22 \% \\
3.30 \% \\
5.70 \%\end{array}$ & $\begin{array}{l}0.98 \pm 0.06 \\
11.3 \pm 1.03 \\
180 \pm 31.8\end{array}$ & $\begin{array}{c}6.12 \% \\
9.11 \% \\
17.6 \%\end{array}$ & $\begin{array}{c}8.89 \% \\
7.62 \% \\
20.0 \%\end{array}$ \\
\hline MDMA & $\begin{array}{l}0.18 \\
10.5 \\
27.0\end{array}$ & $\begin{array}{l}0.19 \pm 0.0 \\
11.0 \pm 0.82 \\
29.1 \pm 2.81\end{array}$ & $\begin{array}{l}6.25 \% \\
7.45 \% \\
9.66 \%\end{array}$ & $\begin{array}{l}7.94 \% \\
4.76 \% \\
7.74 \%\end{array}$ & $\begin{array}{l}0.18 \pm 0.01 \\
9.56 \pm 0.95 \\
24.7 \pm 2.70\end{array}$ & $\begin{array}{l}5.57 \% \\
9.94 \% \\
11.0 \%\end{array}$ & $\begin{array}{l}-1.85 \% \\
-8.95 \% \\
-8.67 \%\end{array}$ \\
\hline MDA & $\begin{array}{l}0.75 \\
10.5 \\
45.0\end{array}$ & $\begin{array}{l}0.79 \pm 0.08 \\
11.2 \pm 0.56 \\
48.9 \pm 3.37\end{array}$ & $\begin{array}{c}10.7 \% \\
4.96 \% \\
6.90 \%\end{array}$ & $\begin{array}{l}5.04 \% \\
6.84 \% \\
8.61 \%\end{array}$ & $\begin{array}{l}0.72 \pm 0.05 \\
11.3 \pm 1.03 \\
47.6 \pm 4.64\end{array}$ & $\begin{array}{l}6.44 \% \\
9.15 \% \\
9.75 \%\end{array}$ & $\begin{array}{r}-4.10 \% \\
7.54 \% \\
5.80 \%\end{array}$ \\
\hline MDEA & $\begin{array}{l}0.75 \\
10.5 \\
45.0\end{array}$ & $\begin{array}{l}0.78 \pm 0.06 \\
10.7 \pm 0.52 \\
49.7 \pm 2.95\end{array}$ & $\begin{array}{l}7.69 \% \\
4.86 \% \\
5.94 \%\end{array}$ & $\begin{array}{l}3.82 \% \\
1.90 \% \\
10.5 \%\end{array}$ & $\begin{array}{l}0.84 \pm 0.11 \\
11.6 \pm 0.70 \\
52.3 \pm 6.48\end{array}$ & $\begin{array}{c}13.1 \% \\
6.04 \% \\
12.4 \%\end{array}$ & $\begin{array}{l}12.0 \% \\
10.2 \% \\
16.2 \%\end{array}$ \\
\hline $\begin{array}{l}\text { Flunitrazepam and metabol } \\
\text { Flunitrazepam }\end{array}$ & $\begin{array}{l}0.75 \\
10.5 \\
45.0\end{array}$ & $\begin{array}{l}0.70 \pm 0.00 \\
10.4 \pm 0.18 \\
47.5 \pm 2.11\end{array}$ & $\begin{array}{l}0.01 \% \\
1.69 \% \\
4.45 \%\end{array}$ & $\begin{array}{r}-7.32 \% \\
-1.17 \% \\
5.44 \%\end{array}$ & $\begin{array}{l}0.75 \pm 0.03 \\
10.4 \pm 0.64 \\
46.8 \pm 4.18\end{array}$ & $\begin{array}{l}4.52 \% \\
6.15 \% \\
8.94 \%\end{array}$ & $\begin{array}{r}0.33 \% \\
-0.62 \% \\
4.01 \%\end{array}$ \\
\hline 7-Aminoflunitrazepam & $\begin{array}{l}0.18 \\
10.5 \\
27.0\end{array}$ & $\begin{array}{l}0.20 \pm 0.00 \\
11.3 \pm 0.53 \\
29.5 \pm 1.80\end{array}$ & $\begin{array}{l}2.40 \% \\
4.73 \% \\
6.10 \%\end{array}$ & $\begin{array}{l}9.09 \% \\
7.50 \% \\
9.38 \%\end{array}$ & $\begin{array}{l}0.17 \pm 0.01 \\
10.5 \pm 0.15 \\
27.6 \pm 1.46\end{array}$ & $\begin{array}{l}9.10 \% \\
1.47 \% \\
5.29 \%\end{array}$ & $\begin{array}{r}-5.45 \% \\
0.33 \% \\
2.30 \%\end{array}$ \\
\hline$N$-Desmethylflunitrazepam & $\begin{array}{c}0.90 \\
10.5 \\
150\end{array}$ & $\begin{array}{l}0.95 \pm 0.00 \\
10.6 \pm 0.79 \\
167 \pm 7.50\end{array}$ & $\begin{array}{l}0.01 \% \\
7.50 \% \\
4.48 \%\end{array}$ & $\begin{array}{l}5.93 \% \\
0.77 \% \\
11.6 \%\end{array}$ & $\begin{array}{l}0.85 \pm 0.04 \\
10.7 \pm 0.28 \\
164 . \pm 11.1\end{array}$ & $\begin{array}{l}4.91 \% \\
2.63 \% \\
6.75 \%\end{array}$ & $\begin{array}{r}-6.05 \% \\
1.44 \% \\
9.36 \%\end{array}$ \\
\hline $\begin{array}{l}\text { Cocaine and metabolites } \\
\text { Cocaine }\end{array}$ & $\begin{array}{l}0.18 \\
10.5 \\
27.0\end{array}$ & $\begin{array}{l}0.19 \pm 0.01 \\
11.2 \pm 1.09 \\
30.7 \pm 3.56\end{array}$ & $\begin{array}{l}6.88 \% \\
9.73 \% \\
11.6 \%\end{array}$ & $\begin{array}{c}8.24 \% \\
6.67 \% \\
13.7 \%\end{array}$ & $\begin{array}{l}0.19 \pm 0.01 \\
11.0 \pm 0.92 \\
28.7 \pm 1.80\end{array}$ & $\begin{array}{l}6.23 \% \\
8.34 \% \\
6.28 \%\end{array}$ & $\begin{array}{l}6.52 \% \\
4.93 \% \\
6.30 \%\end{array}$ \\
\hline Norcocaine & $\begin{array}{l}0.18 \\
10.5 \\
27.0\end{array}$ & $\begin{array}{l}0.18 \pm 0.00 \\
9.61 \pm 1.19 \\
29.4 \pm 1.69\end{array}$ & $\begin{array}{l}0.01 \% \\
12.4 \% \\
5.74 \%\end{array}$ & $\begin{array}{r}1.41 \% \\
-8.43 \% \\
8.87 \%\end{array}$ & $\begin{array}{l}0.20 \pm 0.02 \\
11.8 \pm 0.50 \\
29.8 \pm 1.97\end{array}$ & $\begin{array}{l}10.0 \% \\
4.19 \% \\
6.60 \%\end{array}$ & $\begin{array}{l}11.1 \% \\
12.7 \% \\
10.5 \%\end{array}$ \\
\hline Benzoylecgonine & $\begin{array}{l}0.18 \\
10.5 \\
27.0\end{array}$ & $\begin{array}{l}0.17 \pm 0.02 \\
9.75 \pm 0.68 \\
25.2 \pm 0.18\end{array}$ & $\begin{array}{l}8.96 \% \\
6.94 \% \\
0.71 \%\end{array}$ & $\begin{array}{r}-3.54 \% \\
-7.15 \% \\
6.56 \%\end{array}$ & $\begin{array}{l}0.18 \pm 0.01 \\
11.1 \pm 0.16 \\
26.4 \pm 1.30\end{array}$ & $\begin{array}{l}5.62 \% \\
1.41 \% \\
4.91 \%\end{array}$ & $\begin{array}{r}1.70 \% \\
5.28 \% \\
-2.18 \%\end{array}$ \\
\hline Ecgonine methyl ester & $\begin{array}{c}27.0 \\
75 \\
750 \\
3000\end{array}$ & $\begin{array}{l}21.1 \pm 3.81 \\
- \\
- \\
-\end{array}$ & $\begin{array}{l}18.1 \% \\
- \\
- \\
-\end{array}$ & $\begin{array}{c}-21.8 \% \\
- \\
- \\
-\end{array}$ & $\begin{array}{l}- \\
75.3 \pm 5.01 \\
799 \pm 63.2 \\
3104 \pm 165\end{array}$ & $\begin{array}{l}- \\
6.92 \% \\
7.92 \% \\
5.31 \%\end{array}$ & $\begin{array}{r}- \\
-3.57 \% \\
6.47 \% \\
3.47 \%\end{array}$ \\
\hline Cocaethylene & $\begin{array}{l}0.18 \\
10.5 \\
27.0\end{array}$ & $\begin{array}{l}0.16 \pm 0.02 \\
11.7 \pm 1.02 \\
30.2 \pm 2.52\end{array}$ & $\begin{array}{l}10.7 \% \\
8.70 \% \\
8.34 \%\end{array}$ & $\begin{array}{r}-12.2 \% \\
11.6 \% \\
11.9 \%\end{array}$ & $\begin{array}{l}0.20 \pm 0.01 \\
11.2 \pm 1.28 \\
29.2 \pm 0.90\end{array}$ & $\begin{array}{l}4.57 \% \\
11.4 \% \\
3.10 \%\end{array}$ & $\begin{array}{l}9.44 \% \\
7.06 \% \\
7.96 \%\end{array}$ \\
\hline
\end{tabular}

Increasing the corona current did not improve signals of the analytes on APCI. We found that the single intensity of most analytes was the highest when the corona current was at $0.1-0.3 \mu \mathrm{A}$ for both the standards and the samples. The response of most analyte standards decreased when corona currents were increased. It has been suggested that with an increase in corona current, more protonated water ions $\left(\left[\mathrm{H}_{3} \mathrm{O}\right]^{+}\right)$would be available for proton transfer and ionization would be made more efficient [52]. This was not the case in our study.

Our results suggested that the abundance ratios of quantitative ions to confirmatory ions in oral fluid samples would not be so close to those in standards at trace levels (around $1 \mathrm{ng} / \mathrm{mL}$ ) than at 
higher concentrations, and the ratios less varied on ESI than those on APCI and APPI. On ESI, the average ion abundance ratios of most analytes in oral fluid $(n=4)$ were within $19 \%$ of that in standards at the low spiked levels except for MDEA, 7-aminoflunitrazepam and cocaethylene. As the spiked concentrations increased, the average ratios in the samples more closely approximated those of the standards. On APCI, only the average ion abundance ratios of MDA, MDEA, 7-aminoflunitrazepam, $N$-desmethylflunitrazepam, cocaine and norcocaine in oral fluid were found to be within $20 \%$ of those in standards at the low spiked levels. The average ratios of most analytes at the medium and high levels were within $25 \%$ and $21 \%$ of those of the standards, respectively, except for 6-acetylmorphine, codeine, and methamphetamine. On APPI, only the average ion abundance ratios of heroin, flunitrazepam, cocaine and norcocaine were below $22 \%$ at the low spiked level. The average ratios were within $24 \%$ of those of the standards at the medium and high levels except for 6-acetylmorphine and benzoylecgonine. Bueno et al. also observed that the relative abundance among product ions varied with different concentrations and matrixes [53]. Using ESI, Fritch et al. required the product ion ratio of quantitation to qualification with $\pm 25 \%$ that of calibration standards [31]; three-fourth of their analytes at the lowest concentrations equaled $10 \mathrm{ng} / \mathrm{mL}$ or higher in the oral fluid.

Our methods were accurate and precise as evidenced by our finding that most biases and RSDs $(n=4)$ at the three spiked levels were smaller than 15\%. Ninety-six percent of the biases on ESI were smaller than $20 \%$ (Table 4). Seventy-seven percent and 95\% of the biases on APCI and APPI were smaller than $10 \%$ and $15 \%$, respectively (Table 5). All RSDs on ESI and APPI were smaller than $15 \%$ except for one spiked level at 6-acetylmorphine, benzoylecgonine, and amphetamine $(\approx 17.5 \%$ ) (Tables 4 and 5 ). On APCI, $85 \%$ and $98 \%$ of the RSDs were smaller than $10 \%$ and $15 \%$, respectively (Table 5). The intra-day RSDs were equal to or smaller than $15 \%$ and the inter-day RSDs were all smaller than $17 \%$ ( $n=3$; details were not shown).

\section{Conclusions}

This study developed and validated a method using UHPLCMS/MS to detect 17 illicit drugs in only $100-\mu \mathrm{L}$ oral fluid and was sensitive enough to provide LODs reaching sub-ppb levels at three atmospheric pressure ionization sources. The throughput was significantly increased by simplifying the pretreatment process and the chromatographic run was shortened to $7.5 \mathrm{~min}$. This method makes it possible to handle a large number of oral-fluid samples containing trace amounts of illicit drugs and makes it possible to detect these drugs in oral fluids longer after their use, which makes it especially useful for forensic applications.

APPI can potentially be used to analyze small molecules, and is not limited to relatively nonpolar chemicals. Because of inconsistent matrix effects among the analytes and the ionization probes, we suggest the use of isotope-labeled internal standards or matrixmatched calibration for quantifying illicit drugs in oral fluids. Further investigations are required to determine the causes of higher ion suppression on APCI and APPI than on ESI from oral fluid, which is supposed to be a much simpler matrix than others such as serum and urine. Considering matrix effects, limits of quantitation and accessibility together, we would suggest using ESI for analyzing illicit drugs in the oral fluid.

\section{Acknowledgements}

This study was supported by the National Bureau of Controlled Drugs, Department of Health, Taiwan (project number DOH97NNB-1014). The UHPLC-MS/MS was provided by the Center for
Environment and Occupational Health Research, College of Public Health, National Taiwan University.

\section{Appendix A. Supplementary data}

Supplementary data associated with this article can be found, in the online version, at doi:10.1016/j.jchromb.2010.09.014.

\section{References}

[1] United Nations Office on Drugs and Crime, World Drug Report, 2008, available: http://www.unodc.org/documents/wdr/WDR_2008/WDR_2008_eng_web.pdf.

[2] E. Gallardo, M. Barroso, J.A. Queiroz, Drug Test. Anal. 1 (2009) 109.

[3] E. Cognard, S. Bouchonnet, C. Staub, J. Pharm. Biomed. Anal. 41 (2006) 925.

[4] V. Spiehler, Clarke's Analysis of Drugs and Poisons in Pharmaceuticals, in: Body Fluids and Postmortem Material, Pharmaceutical Press, London, 2004.

[5] O.H. Drummer, Ther. Drug Monit. 30 (2008) 203.

[6] T. Gunnar, K. Ariniemi, P. Lillsunde, J. Mass Spectrom. 40 (2005) 739.

[7] F.M. Wylie, H. Torrance, R.A. Anderson, J.S. Oliver, Forensic Sci. Int 150 (2005) 191.

[8] W. Schramm, P.A. Craig, R.H. Smith, G.E. Berger, Clin. Chem. 39 (1993) 481.

[9] K. Kato, M. Hillsgrove, L. Weinhold, D.A. Gorelick, W.D. Darwin, E.J. Cone, J. Anal. Toxicol. 17 (1993) 338.

[10] A.J. Jenkins, J.M. Oyler, E.J. Cone, J. Anal. Toxicol. 19 (1995) 359.

[11] P. Kintz, V. Cirimele, B. Ludes, J. Anal. Toxicol. 24 (2000) 557.

[12] E.J. Cone, J. Clarke, L. Tsanaclis, J. Anal. Toxicol. 31 (2007) 424

[13] R. Jufer, S.L. Walsh, E.J. Cone, A. Sampson-Cone, J. Anal. Toxicol. 30 (2006) 458

14] O.H. Drummer, The Forensic Pharmacology of Drugs of Abuse, Oxford University Press, New York, 2001.

[15] R. Dams, R.E. Choo, W.E. Lambert, H. Jones, M.A. Huestis, Drug Alcohol Depend. 87 (2006) 258.

[16] I. Kim, A.J. Barnes, J.M. Oyler, R. Schepers, R.E. Joseph, E.J. Cone, D. Lafko, E.T. Moolchan, M.A. Huestis, Clin. Chem. 48 (2002) 1486.

[17] S.L. Kacinko, A.J. Barnes, I. Kim, E.T. Moolchan, L. Wilson, G.A. Cooper, C. Reid, D. Baldwin, C.W. Hand, M.A. Huestis, Forensic Sci. Int. 141 (2004) 41.

[18] R.J.F. Schepers, J.M. Oyler, R.E. Joseph, E.J. Cone, E.T. Moolchan, M.A. Huestis, Clin. Chem. 49 (2003) 121

[19] M.A. Huestis, E.J. Cone, Conference on Oral-Based Diagnostics, 2006 p. 104.

[20] M. Navarro, S. Pichini, M. Farre, J. Ortuno, P.N. Roset, J. Segura, R. de la Torre Clin. Chem. 47 (2001) 1788.

[21] N. Samyn, G. De Boeck, M. Wood, C.T. Lamers, D. De Waard, K.A. Brookhuis, A.G. Verstraete, W.J. Riedel, Forensic Sci. Int. 128 (2002) 90.

[22] N. Samyn, G. De Boeck, V. Cirimele, A. Verstraete, P. Kintz, J. Anal. Toxicol. 26 (2002) 211.

[23] E.J. Cone, M. Hillsgrove, W.D. Darwin, Clin. Chem. 40 (1994) 1299.

[24] K.B. Scheidweiler, M.A. Huestis, J. Chromatogr. B 835 (2006) 90

[25] N. Fucci, N. De Giovanni, M. Chiarotti, Forensic Sci. Int. 134 (2003) 40

[26] P. Meng, Y. Wang, Forensic Sci. Int. 197 (2010) 80.

[27] A. Kankaanpää, T. Gunnar, K. Ariniemi, P. Lillsunde, S. Mykkänen, T. Seppälä, J. Chromatogr. B 810 (2004) 57.

[28] M. Wood, M. Laloup, M. Ramirez Fernandez Mdel, K.M. Jenkins, M.S. Young J.G. Ramaekers, G. De Boeck, N. Samyn, Forensic Sci. Int. 150 (2005) 227.

[29] K.A. Mortier, K.E. Maudens, W.E. Lambert, K.M. Clauwaert, J.F. Van Bocxlaer D.L. Deforce, C.H. Van Peteghem, A.P. De Leenheer, J. Chromatogr. B $779(2002)$ 321.

[30] M. Wood, G. De Boeck, N. Samyn, M. Morris, D.P. Cooper, R.A.A. Maes, E.A. De Bruijn, J. Anal. Toxicol. 27 (2003) 78.

[31] D. Fritch, K. Blum, S. Nonnemacher, B.J. Haggerty, M.P. Sullivan, E.J. Cone, J. Anal. Toxicol. 33 (2009) 569.

[32] P. Lillsunde, Ther. Drug Monit. 30 (2008) 181.

[33] M. Concheiro, A. de Castro, O. Quintela, A. Cruz, M. Lopez-Rivadulla, Anal. Bioanal. Chem. 391 (2008) 2329.

[34] H.H. Maurer, Anal. Bioanal. Chem. 388 (2007) 1315

35] H.H. Maurer, Anal. Bioanal. Chem. 381 (2005) 110.

[36] N. Samyn, M. Laloup, G. De Boeck, Anal. Bioanal. Chem. 388 (2007) 1437.

[37] R. Dams, M.A. Huestis, W.E. Lambert, C.M. Murphy, J. Am. Soc. Mass Spectrom $14(2003) 1290$

[38] E.L. Oiestad, U. Johansen, A.S. Christophersen, Clin. Chem. 53 (2007) 300.

[39] R. Dams, C.M. Murphy, R.E. Choo, W.E. Lambert, A.P. De Leenheer, M.A. Huestis, Anal. Chem. 75 (2003) 798.

[40] D.B. Robb, T.R. Covey, A.P. Bruins, Anal. Chem. 72 (2000) 3653.

[41] Y.X. Cai, D. Kingery, O. McConnell, A.C. Bach, Rapid Commun. Mass Spectrom. 19 (2005) 1717.

[42] M.R. Boleda, M.T. Galceran, F. Ventura, J. Chromatogr. A 1175 (2007) 38

[43] M.E. Swartz, J. Liq. Chromatogr. Relat. Technol. 28 (2005) 1253.

[44] K. Langel, C. Engblom, A. Pehrsson, T. Gunnar, K. Ariniemi, P. Lillsunde, J. Anal. Toxicol. 32 (2008) 393.

[45] Commission Decision of 12 August 2002 implementing Council Directive 96/23/EC Concerning the Performance of Analytical Methods and the Interpretation of Results, Off. J. Eur. Communities, L221 (2002) the Interpretation of Results, Off. J. Eur. Communities, L221 (2002)
8 , available: 22120020817en00080036.pdf. 
[46] S.S. Simões, A.C. Ajenjo, J.M. Franco, D.N. Vieira, M.J. Dias, Rapid Commun. Mass Spectrom. 23 (2009) 1451.

[47] M. Sergi, E. Bafile, D. Compagnone, R. Curini, G. D’Ascenzo, F.S. Romolo, Anal. Bioanal. Chem. 393 (2009) 709.

[48] N. Badawi, K.W. Simonsen, A. Steentoft, I.M. Bernhoft, K. Linnet, Clin. Chem. 55 (2009) 2004.

[49] J.K.M. Aps, L.C. Martens, Forensic Sci. Int. 150 (2005) 119.
[50] R.M. Nagler, O. Hershkovich, S. Lischinsky, E. Diamond, A.Z. Reznick, J. Invest. Med. 50 (2002) 214.

[51] A. Raffaelli, A. Saba, Mass Spectrom. Rev. 22 (2003) 318.

[52] W.M.A. Niessen, Liquid Chromatography-Mass Spectrometry, Marcel Dekker, New York, 1999.

[53] M.J.M. Bueno, A. Agüera, M.D. Hernando, M.J. Gómez, A.R. Fernández-Alba, J. Chromatogr. A 1216 (2009) 5995. 